\title{
Obesity Reduction Black Intervention Trial (ORBIT): 18-Month Results
}

\author{
Marian L. Fitzgibbon ${ }^{1,2,3}$, Melinda R. Stolley ${ }^{1,3}$, Linda Schiffer ${ }^{1}$, Lisa K. Sharp ${ }^{1}$, Vicky \\ Singh ${ }^{1}$, and Alan Dyer ${ }^{4}$ \\ ${ }^{1}$ University of Illinois at Chicago, Department of Medicine, Chicago, IL \\ 2University of Illinois at Chicago, School of Public Health, Chicago, IL \\ ${ }^{3}$ Jesse Brown VA Medical Center, Center for Management of Complex Chronic Care, Chicago, IL \\ ${ }^{4}$ Northwestern University, Feinberg School of Medicine, Chicago, IL
}

\begin{abstract}
Obesity is a chronic condition that is prevalent in black women. The Obesity Reduction Black Intervention Trial (ORBIT) was a randomized controlled weight loss and weight loss maintenance trial. Participants $(\mathrm{N}=213)$ were randomized to the intervention or control groups in August 2005 and September 2006. Follow-up data were collected 6 and 18 months after randomization. The main outcome was change in weight and body mass index from baseline to 18 months. The mean weight at baseline was $104.9 \mathrm{~kg}$ and the mean weight loss in the intervention group at 6 months was $3.0 \mathrm{~kg}$ and a gain of $0.2 \mathrm{~kg}$ in the control group (mean difference between groups in weight change at 6 months, adjusting for baseline weight and cohort, $-3.27 \mathrm{~kg} ; 95 \%$ confidence interval [CI], -4.50 to $-2.05 \mathrm{~kg} ; \mathrm{P}<.001$ ). Both groups gained weight between 6 and 18 months (mean 1.0 $\mathrm{kg}$ in the intervention group and $0.1 \mathrm{~kg}$ in the control group). However, intervention participants lost significantly more weight than control participants during the 18 month intervention (adjusted mean difference between groups at 18 months, $-2.83 \mathrm{~kg}$; $95 \% \mathrm{CI},-4.71$ to $-0.95 ; \mathrm{P}=.003$ ). At 18 months, intervention participants were more likely than control participants to have lost at least $5 \%$ of baseline weight ( $24 \%$ vs. $12 \%, \mathrm{P}<.04$ ). Our results indicate that the ORBIT program did promote weight loss and weight loss maintenance. However, the results also clearly illustrate there is more to learn about what will contribute to meaningful weight loss and maintenance in this population.
\end{abstract}

\section{Keywords}

Diet; physical activity; minorities; weight loss; weight loss maintenance

\section{INTRODUCTION}

The prevalence of obesity has risen dramatically over the past 30 years, and more than $32 \%$ of adults in the United States are now considered obese (body mass index (BMI) $\geq 30 \mathrm{~kg}$ / $\mathrm{m}^{2}$ ). (1) Prevalence is considerably higher among black women, with $54 \%$ classified as obese compared to $30 \%$ of white women. (1) Obesity is linked to a number of chronic

Corresponding Author: Marian L. Fitzgibbon, University of Illinois at Chicago, Department of Medicine M/C 275, Section of Health Promotion Research, 1747 West Roosevelt Road, Room 558, Chicago, IL 60608, 312/996-0523 (telephone), 312/413-8950 (fax), mlf@uic.edu.

Disclosure

No financial disclosure information. 
diseases, and Black women in particular experience higher morbidity and mortality than other populations with respect to obesity-related diseases such as hypertension, type 2 diabetes, and certain cancers. (1-3)

The ability to maintain long-term weight control requires permanent adoption of healthful dietary and activity behaviors. Individuals who are successful in maintaining weight loss over time report lower levels of fat consumption, higher levels of physical activity, and regular self-monitoring of weight and food intake. (4) Maintaining contact with intervention participants has also been shown to be an effective tool in reducing or delaying relapse. (5-7)

Despite the fact that black women have a higher prevalence of obesity than other ethnic groups, they are often under-represented in weight loss trials. $(8,9)$ A comprehensive review showed that most studies either included predominantly white samples or did not report the ethnic breakdown of participants. (10) Similarly, most weight loss maintenance studies have not included substantial numbers of black participants, limiting generalizability. $(6,11-16)$

Studies that have focused more specifically on black participants often have small sample sizes, $(17,18)$ large attrition rates $(19)$ or non-randomized designs. $(17,18,20)$ The recently published Weight Loss Maintenance (WLM) trial addressed some of the limitations of previous weight loss maintenance studies by incorporating a randomized design and recruiting a large and diverse sample. (21) However, there is still a need to develop and deliver weight loss and maintenance interventions that will meet the needs of black women. $(22,23)$

This article reports the results of the Obesity Reduction Black Intervention Trial (ORBIT), a randomized controlled trial to test the efficacy of a 6-month weight loss intervention followed by a 12 month weight loss maintenance intervention for obese black women. The intervention, baseline characteristics of participants, and recruitment strategies have been described in detail elsewhere, and interim results from the 6-month weight loss intervention have also been reported. (24-26)

\section{METHODS}

Recruitment and Participant Flow. The study was approved by the Institutional Review Board at the University of Illinois at Chicago (UIC). Recruitment for cohort 1 began in May 2005 and ended in August 2005. Recruitment for cohort 2 began in July 2006 and ended in September 2006. The study was conducted in two cohorts due to resource limitations. Recruitment strategies included a mass e-mail that was sent to all UIC faculty, staff, and students (approximately 36,000 recipients) and face-to-face recruitment that was conducted within a two-mile radius of the intervention site.

Women who were interested in the program were asked to complete a short eligibility interview, either by telephone (86\%) or in person (14\%). To be eligible for the study, a potential participant was required to have a body mass index (BMI), calculated as weight in kilograms divided by height in meters squared, between 30 and 50, to be female, selfidentified as African-American or black, between the ages of 30 and 65 years, able to participate in an activity program requiring 30 minutes of uninterrupted moderate activity, and able to attend class sessions.

Women were excluded if they were unable to exercise because of emphysema, chronic bronchitis, or asthma; if they used a cane, walker, or wheelchair for mobility; if they were planning to move out of the area; if they had been treated for cancer (excluding skin cancer other than melanoma) in the past 5 years; if they were participating in a formal weight loss 
program or taking weight loss medications prescribed by a doctor; if they were pregnant, nursing, or planning a pregnancy; or if they were using illegal drugs or consuming more than 2 alcoholic drinks per day on a daily basis.

Participants were randomized shortly before the intervention began. All women who completed the baseline interview were called before randomization to confirm that they were still able to participate. A morning class and an evening class were offered for cohort 1 , and women were randomized in two separate blocks based on their preferred class. For cohort 2, both classes met in the evening at the same time. Therefore, all participants were randomized to the intervention or control group in a single block, and participants in the intervention group were randomly assigned to one of the two classes. The allocation assignments were generated using a program written by the data analyst, who had no contact with participants.

Data were collected at baseline, after the 6-month weight loss intervention (6 months) and after the 12-month weight loss maintenance intervention (18 months).

\section{Measures}

All data collection personnel were trained and certified in interviewing and anthropometric measurements by a master trainer. All questionnaires were interviewer-administered. At the baseline visit, interviewers were not aware of participants' eventual group assignments, since participants were not randomized until all baseline interviews had been completed. Due to staffing constraints, data collectors were not blinded to group assignment at the 6month and 18-month visits.

Anthropometrics-Height was measured at baseline using a Seca 214 portable stadiometer (Seca, Hanover, MD). Weight was measured at all visits using a Tanita BWB-800 digital scale (Tanita Corporation of America, Inc., Arlington Heights, IL). Participants removed their shoes and any heavy outer clothing for the anthropometric measurements. Both height and weight were measured twice, to the nearest $0.1 \mathrm{~cm}$ and 0.1 $\mathrm{kg}$ respectively. If the two height measurements were more than $0.5 \mathrm{~cm}$ apart or if the two weight measurements were more than $0.2 \mathrm{~kg}$ apart, a third measurement was taken. The mean of the two closest measurements was used for analysis. BMI was computed from height and weight.

Dietary Intake-Dietary intake was measured using the Block '98 Food Frequency Questionnaire (FFQ). (27) The Block FFQ asks about frequency of consumption in the past year and usual portion size for 110 different food items. Data from the FFQ were used to calculate nutrient intake, food group intake, and other dietary variables, including the Healthy Eating Index (HEI). (28) The HEI is a measure of overall diet quality developed by United States Department of Agriculture's (USDA) Center for Nutrition Policy and Promotion. Scores range from 0 to 100, with a higher score reflecting a healthier diet.

Physical Activity-Physical activity was measured using the International Physical Activity Questionnaire-Long Format (IPAQ). (29) The long IPAQ is designed to assess selfreported physical activity during the past 7 days. Participants were asked only to report activity that they engaged in for at least 10 minutes at a time.

\section{Interventions}

The ORBIT weight loss and weight loss maintenance interventions are described in detail elsewhere. $(24,26)$ Briefly, the interventions were developed from focus group data, (30) other weight loss trials we have conducted with black women, $(31,32)$ and information 
available in the literature. $(22,33,34)$ Accordingly, we emphasized social support and dedicated time to sharing experiences. Food and activity recommendations were sensitive to cultural preferences, sessions were interactive, and black peer mentors who had been successful at weight loss maintenance shared their weight loss testimony with the group. Finally, spirituality and religion were woven into discussion on health issues as a way of tailoring motivational messages. Moreover, given that all of the participants and some of the interventionists were black, there were natural cultural adaptations that developed through interactions within the group. The conceptual framework guiding the development and delivery of the intervention was based on Social Cognitive Theory (35) and thus focused on changes in cognitions, behaviors, the environment and social support related to weight loss.

Weight Loss Intervention-The 6-month weight loss intervention was conducted in a group format by trained interventionists. Some of the interventionists were black and others were non-Hispanic white or Asian. The class met twice weekly on the university campus. The women were weighed weekly. The weight loss goal for the first 6 months was $7 \%$ of initial body weight, which would then be maintained throughout the 12-month maintenance intervention. The recommended rate for weight loss was approximately 1-2 lbs per week. All participants were taught behavioral strategies such as self-monitoring and stimulus and portion control to help with both weight loss and weight loss maintenance.

All participants were encouraged to adopt a low-fat, high-fiber diet with increased fruit and vegetable consumption and decreased caloric intake. In feedback sessions conducted during the development of the intervention, former participants in our weight loss trials said that they wanted a program that could be integrated into their lives and the lives of family members. Therefore, highly structured meal plans and meal replacements were not included in the intervention. Participants were encouraged to increase their physical activity. Selfmonitoring of both food and activity were taught, and women were given pedometers and encouraged to walk 10,000 or more steps a day. The intervention was tailored to the individual primarily by feedback on their self-monitoring logs. Between sessions, the interventionists reviewed the logs and were then able to provide more structured and individual guidance on healthier food choices, food preparation techniques and portion sizes.

Participants were also offered a monthly motivational interviewing (MI) session by trained interventionists that addressed either diet or physical activity. $(36,37)$ MI sessions were conducted face-to-face or over the phone, and each session lasted approximately 20-30 minutes. The group facilitators did not use MI during the group meetings.

Women in the control group received newsletters that covered general health and safety topics on a weekly basis throughout the 6-month period. A staff member telephoned control participants once a month to allow participants to ask questions or express concerns about the information contained in the weekly newsletters. This staff member was not an interventionist and was not trained in MI.

Maintenance Intervention-The 12-month weight loss maintenance intervention emphasized structuring one's life in a way that supported maintenance of weight loss behaviors. However, for many of the women who had lost minimal weight during the 6month weight loss intervention, weight loss continued to be a goal. In months 7-12, the group met twice weekly and each member received monthly MI sessions. The topic of each group session was chosen by a participant, which allowed for the material to remain responsive to the needs of the group members and provided them with a sense of ownership. In months 13-15, the group met once weekly for an exercise class, and women continued to receive monthly MI. Finally, in months 16-18, there were no face-to face group meetings, but women continued to receive monthly MI. Because the majority of the women were still 
trying to lose weight during the maintenance period of the study, the MI component did not change substantially over the course of the intervention. During MI sessions, interventionists and participants continued to work on building motivation and commitment and focused on relevant target behaviors (e.g, problem foods and barriers to being physically active.)

Throughout the 12-month maintenance period, participants received newsletters every other month, which reinforced concepts related to health behavior change. Women in the control group received monthly newsletters that covered general health and safety topics throughout the 12-month period. Control group participants also continued to receive monthly phone calls from staff who were not trained in MI.

\section{Outcomes}

The primary outcomes were change in weight and BMI from baseline to the end of the study, 18 months after randomization. We also report the change in weight from baseline to 6 months and 6 to 18 months, along with several dichotomous measures of weight change at 18 months. Changes in diet and physical activity from baseline to 18 months were secondary outcomes. Diet outcomes were changes in energy $(\mathrm{kcal} / \mathrm{d})$, fat $(\% \mathrm{kcal})$, fiber $(\mathrm{g} / 10000 \mathrm{kcal})$, fruit and vegetable consumption (servings/day), and HEI score. Physical activity outcomes were time spent walking and engaging in moderate activity, vigorous activity, and total activity (walking, moderate, and vigorous) ( $\mathrm{min} / \mathrm{d}$ ) at follow-up, controlling for the baseline value.

\section{Statistical Methods}

Analysis of covariance was used to test for differences between groups in weight change and BMI change from baseline to 18 months, adjusting for cohort and baseline weight or BMI. A similar model was used to compare differences between groups in change from baseline to 6 months. When testing for differences between groups in change from 6 to 18 months, change from baseline to 6 months was added to the model as a covariate. Models including a cohort by group interaction term were used to test for differences between cohorts in response to the intervention at 18 months.

Only participants with weight measurements at 18 months were included in the primary analysis. However, we also conducted a sensitivity analysis in which we used multiple imputation (38) to account for missing weight measurements at 6 and 18 months using IVEWare in SAS. The imputation model included weight at baseline, 6 months, and 18 months as well as cohort, age, years of education, and height. In one version of the analysis, weights were imputed for all 23 participants with missing data at 18 months. In a second version, 4 women were excluded from the analysis: 1 who had died, 1 with colon cancer, and 2 who were pregnant at 18 months. Five complete datasets were created and analyzed separately. The results of the 5 analyses were combined by calculating the average of the estimated differences across the 5 data sets, and by adjusting the standard error of the combined estimate for the variation in the estimates across the 5 data sets. (39)

Analysis of covariance was also used to test for differences between groups in change in dietary intake, controlling for cohort and the baseline value. Participants who reported total energy $<500 \mathrm{kcal} / \mathrm{day}$ or $>5000 \mathrm{kcal} / \mathrm{day}$ at baseline or follow-up were excluded from all analyses of dietary intake, since those records were considered invalid. The physical activity variables were treated somewhat differently. All physical activity variables were logtransformed to improve normality, after adding 1 to all values to eliminate values of 0 . Analysis of covariance was used to test for differences in log-transformed values at 18 months, adjusted for cohort and the log-transformed baseline value. Approximate adjusted 
geometric means at 18 months were calculated by exponentiating the least-squares means from the analysis of covariance, then subtracting 1 from the result.

Differences in baseline characteristics between the intervention and control groups and between participants with and without 18-month weight data were tested for significance using the Wilcoxon rank sum test for income, t-tests for all other continuous variables, and chi-square tests for employment and marital status. Spearman's correlation coefficients were used to test for associations between weight change and class attendance among women in the intervention group.

The planned sample size of 100 per group was selected to provide $90 \%$ power to detect a difference of 1.1 to $1.25 \mathrm{~kg} / \mathrm{m}^{2}$ in change in BMI between the intervention and control groups at 18 months, assuming a two-sided test at the 5\% level. Power calculations also assumed that at least $85 \%$ of the women would provide data at 18 months and that the standard deviation of change in BMI would be between 2.2 and $2.5 \mathrm{~kg} / \mathrm{m}^{2}$.

All analyses were conducted using SAS version 9.1 (SAS Institute Inc., Cary, North Carolina). The multiple imputation was conducted using IVEWare with SAS (http:// www.isr.umich.edu/src/smp/ive/). All $\mathrm{P}$ values are 2 sided.

\section{RESULTS}

A total of 213 women were randomized to the intervention group or the control group: 117 in cohort 1 and 96 in cohort 2 (Figure 1). Weight at follow-up was measured for 197 women $(92 \%)$ at the 6-month visit and for 190 women (89\%) at the 18-month visit. The 23 women with missing weight data at 18 months reported somewhat lower income at baseline than the 190 women with 18 -month weight data (median $=\$ 30,000$ vs. $\$ 42,500 ; \mathrm{P}=.04$ ), but there were no other significant differences.

The baseline characteristics of the randomized participants are shown in Table 1 and are described in more detail elsewhere. (24) Mean age was $46.0(\mathrm{SD}=8.4)$ years. The majority (72\%) were employed full-time, and almost half (44\%) had a college degree. The mean BMI was $39.2(\mathrm{SD}=5.7) \mathrm{kg} / \mathrm{m}^{2}$, and $44 \%$ of participants had a BMI $\geq 40 \mathrm{~kg} / \mathrm{m}^{2}$.

Table 2 shows class attendance among the 107 women randomized to the intervention group. During the 6-month weight loss intervention, participants attended 53\% of classes, on average, and $58 \%$ of participants attended at least half of the classes offered. Attendance fell during the maintenance phase of the study. On average, participants attended $27 \%$ of the classes, and $30 \%$ of participants attended at least half of the classes offered. There was a significant correlation between attendance during the first 6 months and overall weight loss at 18 months $(\mathrm{N}=93$, Spearman's $\mathrm{r}=0.31, \mathrm{P}=.003)$. There was also a significant correlation between attendance during the maintenance phase and weight loss from baseline to 18 months $(\mathrm{N}=93$, Spearman's $\mathrm{r}=0.35, \mathrm{P}<.001)$. However, there was not a significant correlation between weight loss from 6 to 18 months and attendance during the maintenance period $(\mathrm{N}=93$, Spearman's $\mathrm{r}=0.06, \mathrm{P}=.54)$.

During the first 6 months of the program, participants completed an average of $3.2(\mathrm{SD}=$ 2.0) of the 6 motivational interviewing sessions offered. Mean MI session completion fell to $2.0(\mathrm{SD}=2.1)$ of 6 sessions during months 7-12. The correlation between MI completion during the first 6 months and overall weight loss at 18 months was not significant $(\mathrm{N}=93$, Spearman's $r=0.19, \mathrm{P}=.07$ ). However, there was a significant correlation between MI completion during months 7-12 of the maintenance phase and weight loss from baseline to 18 months $(\mathrm{N}=93$, Spearman's $\mathrm{r}=0.25, \mathrm{P}=.02)$. 


\section{Weight Outcomes}

As shown in Table 3 and reported elsewhere (26) weight loss at 6 months was significantly greater in the intervention group than in the control group. Women in the intervention group lost $3.04 \mathrm{~kg}$, compared to a $0.22 \mathrm{~kg}$ gain in the control group, and the adjusted difference between groups was $-3.27 \mathrm{~kg}(\mathrm{P}<.001)$. However, both groups gained weight, on average, between 6 and 18 months, and there was not a significant difference between groups in adjusted weight change (unadjusted mean weight gain, $1.01 \mathrm{~kg}$ in the intervention group and $0.15 \mathrm{~kg}$ in the control group; difference in adjusted mean change between groups, $0.29 \mathrm{~kg}, \mathrm{P}$ $=.73$ ). Unadjusted mean weight loss from baseline to 18 months was $2.26 \mathrm{~kg}$ in the intervention group, compared to a gain of $0.51 \mathrm{~kg}$ in the control group, and the adjusted difference between groups was $-2.83 \mathrm{~kg}(\mathrm{P}=.003)$. Responses to the intervention at 18 months did not differ significantly between cohorts $(\mathrm{p}=.19$ for the cohort by group interaction in the analysis of covariance model for weight change).

While participants with missing weight at follow-up were excluded from the analyses shown in Table 3, we also conducted a sensitivity analysis, using multiple imputation to replace missing weight measurements at 6 and 18 months. We used weight at 6 months in the imputations because it was related to weight at 18 months and because change in weight from baseline to 6 months was used as a covariate in the analyses. The results of analyses using multiple imputed values were very similar to those reported in Table 3. For example, when weights were imputed for all 16 participants with missing data at 6 months, the difference between groups in adjusted weight change at 6 months was $-3.18 \mathrm{~kg}(\mathrm{~N}=213$, $95 \%$ CI, -4.43 to $-1.93, \mathrm{P}<.001)$. Similarly, when weights were imputed for all 23 participants with missing data at 18 months, the difference between groups in adjusted weight change from baseline to 18 months was $-2.59 \mathrm{~kg}(\mathrm{~N}=213,95 \% \mathrm{CI},-4.40$ to $-0.78, \mathrm{p}$ $=.005)$. The multiple imputation analysis was then repeated, excluding 4 intervention participants who did not have meaningful weight values to impute at 18 months; 1 was dead, 2 were pregnant, and 1 had colon cancer. This analysis yielded similar results. With $\mathrm{N}=209$, the adjusted difference in weight change between groups at 6 months was $-3.26 \mathrm{~kg}$ (95\% CI, -4.49 to $-2.03, \mathrm{P}<.001$ ), and the adjusted difference between groups at 18 months was -2.68 $\mathrm{kg}(95 \% \mathrm{CI},-4.64$ to $-0.71, \mathrm{P}=.008)$.

As shown in Table 4, $80 \%$ of participants in the intervention group were at or below their baseline weight at 6 months, compared to $39 \%$ in the control group $(\mathrm{P}<.001)$. At 18 months, 58\% of intervention group participants were at or below their baseline weight, though this was still significantly higher than the proportion in the control group $(40 \%, \mathrm{P}=$. $01)$. Intervention participants were somewhat less likely than control participants to end the study at or below their weight at 6 months $(\mathrm{P}=.02)$. Twenty six percent of the women in the intervention group and $5 \%$ of the women in the control group lost $5 \%$ or more of their baseline weight in the first 6 months $(\mathrm{P}<0.001)$. At 18 months, a similar proportion of the intervention group (24\%) and a somewhat higher proportion of the control group (12\%) were at least $5 \%$ below their baseline weight $(\mathrm{P}=.04)$.

\section{Dietary Intake Outcomes}

Changes in dietary intake at 6 months have been described elsewhere. (26) Briefly, there were no significant differences between groups in adjusted change in consumption of energy (kcal/day), fat (\% kcal), fiber $(\mathrm{g} / 1000 \mathrm{kcal})$, or vegetables (servings/day). However, both fruit consumption and HEI score increased significantly more in the intervention group than in the control group at 6 months, controlling for cohort and baseline value. (26) The difference between groups in adjusted mean change was 0.44 servings/day for fruit consumption $(\mathrm{N}=182,95 \% \mathrm{CI}, 0.13$ to $0.76, \mathrm{P}=.006)$ and 5.60 for HEI score $(\mathrm{N}=182$, $95 \% \mathrm{CI}, 2.38$ to $8.82, \mathrm{P}<.001)$. At 18 months, there was no significant difference between 
groups for any dietary variable except HEI score, which increased more in the intervention group than in the control group. Unadjusted mean (SD) change from baseline to 18 months was 8.1 (13.5) in the intervention group and $1.0(11.4)$ in the control group; adjusted difference between groups was $5.16(\mathrm{~N}=176,95 \% \mathrm{CI}, 2.03$ to $8.30, \mathrm{P}=.001)$.

\section{Physical Activity Outcomes}

As described elsewhere, (26) at 6 months, intervention group participants engaged in more moderate $(\mathrm{P}=.05)$, vigorous $(\mathrm{P}<.001)$, and total (walking, moderate, and vigorous activity, $\mathrm{P}=.01$ ) self-reported physical activity than control group participants, adjusting for cohort and the log-transformed baseline value. However, at 18 months, there were no longer any significant differences between groups in self-reported physical activity. The geometric least-squares mean for walking was $22.0 \mathrm{~min} / \mathrm{d}$ in the intervention group and $26.7 \mathrm{~min} / \mathrm{d}$ in the control group $(\mathrm{P}=.34)$; the geometric least-squares mean for moderate activity was 25.8 $\mathrm{min} / \mathrm{d}$ in the intervention group and $35.1 \mathrm{~min} / \mathrm{d}$ in the control group $(\mathrm{P}=.11)$; the geometric least-squares mean for vigorous activity was $5.5 \mathrm{~min} / \mathrm{d}$ in the intervention group and 4.2 $\mathrm{min} / \mathrm{d}$ in the control group $(\mathrm{P}=.30)$; and the geometric least-squares mean for total activity was $70.6 \mathrm{~min} / \mathrm{d}$ in the intervention group and $81.4 \mathrm{~min} / \mathrm{d}$ in the control group $(\mathrm{P}=.40)$.

\section{COMMENT}

To our knowledge, ORBIT is the first randomized trial of a weight loss and maintenance program to focus exclusively on obese black women. The program proved to be effective, with an average weight loss of $3.0 \mathrm{~kg}$ after the 6-month intervention that was relatively well maintained through the 12-month maintenance intervention. Although the weight loss at 18 months was modest, evidence suggests that even very modest weight loss is associated with an improved cardiovascular risk profile (40-45) Weight losses between $2 \%$ and $4 \%$ have been associated with $20 \%$ to $30 \%$ reductions in hypertension, $(46,47)$ and a meta-analysis of 25 randomized controlled trials showed that systolic blood pressure fell by $1.05 \mathrm{~mm} \mathrm{Hg}$ and diastolic blood pressure fell by $0.92 \mathrm{~mm} \mathrm{Hg}$ for every kilogram of weight lost across a wide range of weight loss outcomes. (45) Of particular note, Diabetes Prevention Program (DPP) participants, who all had impaired glucose tolerance at study enrollment, showed a $16 \%$ reduction in diabetes incidence per kilogram of weight lost. (48)

There are few trials directly comparable to ORBIT in target population and study design. ORBIT results compare favorably with results of the Healthy Eating and Lifestyle Program (HELP) (19) and results for black women in the Trials of Hypertension Prevention, Phase II (TOHP II). (43) ORBIT's 6-month weight loss program was apparently somewhat less effective for black women than Phase I of the Weight Loss Maintenance (WLM) trial, (49) and black women also lost more weight at 6 and 18 months in the Diabetes Prevention Program (DPP). $(50,51)$ This could have been because ORBIT recruited women who were generally healthy compared to those recruited to WLM or DPP, and they may have been less motivated to lose weight as a way to improve health.

The HELP study reached a population similar to ORBIT's (African American, 91\% female, mean BMI of $38 \mathrm{~kg} / \mathrm{m}^{2}$ ), though the design was somewhat different. (19) All 237

participants in Phase I of the program received a 10-week weight loss intervention. Those who agreed to participate in Phase II were randomized to one of two maintenance interventions or a usual care control group. A total of 128 participants were randomized, and 87 provided data at the end of Phase II. Also, Phase II varied in length from 8 to 19 months, making it difficult to compare final results with other studies. There was not a significant difference between groups at follow-up, and mean (SD) weight loss was 1.2 (5.2) kg among the 87 participants who completed Phase II. For ORBIT, unadjusted mean weight loss in the intervention group was $2.3(7.4) \mathrm{kg}$ at 18 months. 
TOHP II was a 36-month randomized trial that was similar to ORBIT in that it included an intensive 6-month intervention followed by a less-intensive 30-month intervention. (43) The study was designed to test the efficacy of lifestyle interventions to reduce blood pressure, and approximately $18 \%$ of the 1191 participants were black. At the 18-month assessment, for the black women randomized to the weight loss intervention arm, the mean weight change was $-0.4 \mathrm{~kg}(95 \% \mathrm{CI},-1.6$ to $0.9, \mathrm{~N}=60)$.

In Phase I of the WLM trial, 1685 participants with hypertension, dyslipidemia, or both, including 540 African American women, completed a 6-month intensive weight loss program. (49) Participants who lost at least $4 \mathrm{~kg}$ during Phase I entered Phase II and were randomized to a 30-month maintenance intervention: personal contact, interactive technology, or a self-managed control group. (21) During Phase I, mean weight loss for black women was $4.1 \mathrm{~kg}(\mathrm{SD}=2.9)$, which was somewhat greater than the $3.0 \mathrm{~kg}$ lost by women in the ORBIT intervention group during the 6-month weight loss intervention. However, although the WLM Phase I intervention was successful compared to ORBIT and other weight loss interventions for black women, black women still lost less weight than white men, black men, or white women, and they were less likely to be randomized to Phase II than other groups. (49) It is difficult to compare the WLM Phase II results with the ORBIT results, since only participants who lost $4 \mathrm{~kg}$ during Phase I entered Phase II, and 18-month weight loss is not reported for black women. However, at 30 months from randomization (36 months from entry), mean weight loss for black women was $2.2 \mathrm{~kg}$ in the personal contact group, $1.3 \mathrm{~kg}$ in the interactive technology group, and $1.8 \mathrm{~kg}$ in the selfdirected group. Phase II intervention effects did not differ significantly by sex or race.

The DPP was a large multi-center trial that randomized individuals at high risk for diabetes to receive an intensive lifestyle intervention, metformin, or a placebo. (50) At 6 months, black women randomized to the lifestyle arm had lost $4.7 \mathrm{~kg}(\mathrm{SD}=5.1, \mathrm{~N}=149)$, compared to the $3.0 \mathrm{~kg}$ intervention women lost during the first 6 months of ORBIT. At 18 months, black women participating in the DPP had lost $3.9 \mathrm{~kg}(\mathrm{SD}=6.1, \mathrm{~N}=136)$, compared to $2.3 \mathrm{~kg}$ for ORBIT participants. While black women successfully lost weight in the lifestyle arm of the DPP, they still lost less weight than other groups at all time points.

It is important to note that a sizeable number of women in the control group did not gain weight over the 18-month trial, and 12 control participants (12\%) were at least $5 \%$ below their baseline weight at 18 months. Other interventions have reported similar findings. (52) Interestingly, when participants in the National Weight Control Registry were asked how they had lost at least $30 \mathrm{lbs}$ of excess weight and kept it off for at least one year, approximately $50 \%$ reported losing the weight on their own. (53) It is possible that increased media attention and growing awareness of the link between obesity and poor health could have resulted in enhanced attention to weight loss related behaviors. The monthly calls from an ORBIT staff member following up on the general health curriculum may have had an effect as well.

Several limitations deserve consideration when interpreting the results of this study. Although a strength of this study is the focus on a high-risk population, obesity is a highly prevalent chronic disease across genders and ethnic groups, and our findings are not necessarily generalizable to men or other ethnic groups. We also did not collect systematic data on co-morbid conditions or changes in pharmacologic regimens as a function of weight loss. Nevertheless, some of the participants who lost weight reported that they were able to control their diabetes or hypertension with lower doses of medication or even eliminate the medication altogether. A further limitation of this trial is that dietary intake and physical activity were assessed through self-report. Under-reporting of food intake is problematic, and particularly problematic among obese individuals. $(54,55)$ Just as dietary intake is often 
underreported, physical activity is often over-reported when assessed by self-report. $(56,57)$ More accurate measures of energy intake and energy expenditure are needed, particularly when studying weight loss maintenance. To decrease respondent burden, we did not assess potential mediating variables such as social support, self-efficacy, and intrinsic motivation for weight loss and weight loss maintenance that could have helped us understand some of the possible contextual factors in this high-risk population. Interpretation of our results is also complicated by fairly low levels of attendance at the intervention sessions, especially during the maintenance phase. ORBIT was designed to be an intensive intervention, but the dose each woman received was highly dependent on attendance. During the 6-month weight loss intervention, ORBIT participants were offered 2 classes each week (46 or 47 sessions), but only $58 \%$ of women in the intervention group attended at least half of the offered classes. By contrast, the core curriculum of the DPP consisted of only 16 sessions over 6 months, but $95 \%$ of participants completed all 16 sessions. (51) DPP sessions were delivered one-on-one, which allowed significantly more scheduling flexibility than ORBIT's group sessions. Also, the DPP's enrollment process was far more rigorous than ORBIT's, which could have produced a more highly motivated group of participants.

Overall, the ORBIT results are comparable to other weight loss trials that have included black women. Even though the intervention proved highly successful for many of the participants, the results demonstrate that there is still a great deal we do not know about what will contribute to meaningful weight loss and maintenance in this population. Despite including the target audience in the development of our weight loss and maintenance interventions, the behavior change skills training may not have been sufficiently potent to overcome an environment that is fairly unsupportive of weight control, $(58,59)$ both in terms of exposure to unhealthy foods (60) and limited convenient options for regular physical activity. (61) Finally, the fact that our results are similar to those of other weight loss trials with black women suggests we may have reached the limit of what individual level weight loss trials can produce. Thus, we need to be far more creative in shifting norms through community involvement and establishing "buy in" from multiple levels. We must study health behavior change in a broader context or we will most likely continue to observe relatively modest and short-term benefits. (62-64)

\section{Acknowledgments}

The ORBIT study is supported by the National Cancer Institute (CA105051). We would like to thank all of the women who gave of their time to participate in the study. In addition, we would like to thank the entire ORBIT staff and particularly Maria Caceres, our study coordinator, who worked with the utmost professionalism in conducting this trial. We would also like to thank Guadalupe Compean for her technical assistance.

\section{References}

1. Ogden CL, Carroll MD, Curtin LR, McDowell MA, Tabak CJ, Flegal KM. Prevalence of overweight and obesity in the United States,1999-2004. JAMA. 2006; 295(13):1549-1555. [PubMed: 16595758]

2. Ogden CL, Yanovski SZ, Carroll MD, Flegal KM. The epidemiology of obesity. Gastroenterology. 2007; 132(6):2087-2102. [PubMed: 17498505]

3. Cowie CC, Rust KF, Byrd-Holt DD, et al. Prevalence of diabetes and impaired fasting glucose in adults in the U.S. population: National Health and Nutrition Examination Survey 1999-2002. Diabetes Care. 2006; 29(6):1263-1268. [PubMed: 16732006]

4. Klem ML, Wing RR, McGuire MT, Seagle HM, Hill JO. A descriptive study of individuals successful at long-term maintenance of substantial weight loss. Am J Clin Nutr. 1997; 66(2):239246. [PubMed: 9250100]

5. Harvey-Berino J, Pintauro S, Buzzell P, et al. Does using the internet facilitate the maintenance of weight loss? Int J Obes Relat Metab Disord. 2002; 26(9):1254-1260. [PubMed: 12187404] 
6. Perri MG. The maintenance of treatment effects in the long-term management of obesity. Clin Psychol Sci Pract. 1998; 5(4):526-543.

7. Perri, MG.; Corsica, JA. Improving the maintenance of weight lost in behavioral treatment of obesity. In: Wadden, TA.; Stunkard, AJ., editors. Handbook of Obesity Treatment. Guilford Press; New York: 2002. p. 357-379.

8. Wadden TA, Berkowitz RI, Sarwer DB, Prus-Wisniewski R, Steinberg C. Benefits of lifestyle modification in the pharmacologic treatment of obesity: A randomized trial. Arch Intern Med. 2001; 161(2):218-227. [PubMed: 11176735]

9. Ashley JM, St Jeor ST, Perumean-Chaney S, Schrage J, Bovee V. Meal replacements in weight intervention. Obes Res. 2001; 9(Suppl 4):312S-320S. [PubMed: 11707559]

10. McTigue KM, Hess R, Ziouras J. Obesity in older adults: A systematic review of the evidence for diagnosis and treatment. Obesity. 2006; 14(9):1485-1497. [PubMed: 17030958]

11. Wing RR, Tate DF, Gorin AA, Raynor HA, Fava JL. A self-regulation program for maintenance of weight loss. N Engl J Med. 2006; 355(15):1563-1571. [PubMed: 17035649]

12. Carels RA, Konrad K, Young KM, et al. Taking control of your personal eating and exercise environment: A weight maintenance program. Eat Behav. 2008; 9(2):228-237. [PubMed: 18329602]

13. Jakicic JM, Marcus BH, Lang W, Janney C. Effect of exercise on 24-month weight loss maintenance in overweight women. Arch Intern Med. 2008; 168(14):1550-1559. discussion 1559-1560. [PubMed: 18663167]

14. Perri MG, Nezu AM, Patti ET, McCann KL. Effect of length of treatment on weight loss. J Consult Clin Psychol. 1989; 57(3):450-452. [PubMed: 2500466]

15. Harvey-Berino J, Pintauro S, Buzzell P, Gold EC. Effect of internet support on the long-term maintenance of weight loss. Obes Res. 2004; 12(2):320-329. [PubMed: 14981225]

16. Lutes LD, Winett RA, Barger SD, et al. Small changes in nutrition and physical activity promote weight loss and maintenance: 3-month evidence from the ASPIRE randomized trial. Ann Behav Med. 2008; 35(3):351-357. [PubMed: 18568379]

17. Walcott-McQuigg JA, Chen S-P, Davis K, Stevenson E, Choi A, Wangsrikhun S. Weight loss and weight loss maintenance in African-American women. J Natl Med Assoc. 2002; 94(8):686-694. [PubMed: 12152924]

18. Young DR, Gittelsohn J, Charleston J, Felix-Aaron K, Appel LJ. Motivations for exercise and weight loss among African-American women: Focus group results and their contribution towards program development. Ethn Health. 2001; 6(3-4):227-245. [PubMed: 11696933]

19. Kumanyika SK, Shults J, Fassbender J, et al. Outpatient weight management in AfricanAmericans: The Healthy Eating and Lifestyle Program (HELP) study. Prev Med. 2005; 41(2):488502. [PubMed: 15917045]

20. Karanja N, Stevens VJ, Hollis JF, Kumanyika SK. Steps to Soulful Living (STEPS): A weight loss program for African-American women. Ethn Dis. 2002; 12(3):363-371. [PubMed: 12148707]

21. Svetkey LP, Stevens VJ, Brantley PJ, et al. Comparison of strategies for sustaining weight loss: The Weight Loss Maintenance Randomized Controlled Trial. JAMA. 2008; 299(10):1139-1148. [PubMed: 18334689]

22. Kumanyika S. Obesity, health disparities, and prevention paradigms: Hard questions and hard choices. Prev Chronic Dis. 2005; 2(4):A02. [PubMed: 16164806]

23. Yancey AK, Kumanyika SK, Ponce NA, et al. Population-based interventions engaging communities of color in healthy eating and active living: A review. Prev Chronic Dis. 2004; 1(1):A09. [PubMed: 15634371]

24. Fitzgibbon ML, Stolley M, Schiffer L, et al. Obesity Reduction Black Intervention Trial (ORBIT): Design and baseline characteristics. J Womens Health. 2008; 17(7):1099-1110.

25. Sharp LK, Fitzgibbon ML, Schiffer L. Recruitment of obese black women into a physical activity and nutrition intervention trial. Journal of Physical Activity and Health. 2008; 5(6):870-881. [PubMed: 19164821]

26. Stolley MR, Fitzgibbon ML, Schiffer L, et al. Obesity Reduction Black Intervention Trial (ORBIT): Six-month results. Obesity. 2008; 17(1):100-106. [PubMed: 18997671] 
27. Block G, Woods M, Potosky A, Clifford C. Validation of a self-administered diet history questionnaire using multiple diet records. J Clin Epidemiol. 1990; 43(12):1327-1335. [PubMed: 2254769]

28. Kennedy ET, Ohls J, Carlson S, Fleming K. The Healthy Eating Index: Design and applications. J Am Diet Assoc. 1995; 95(10):1103-1108. [PubMed: 7560680]

29. Craig CL, Marshall AL, Sjöström M, et al. International Physical Activity Questionnaire: 12country reliability and validity. Med Sci Sports Exerc. 2003; 35(8):1381-1395. [PubMed: 12900694]

30. Stolley MR, Sharp LK, Wells AM, Simon N, Schiffer L. Health behaviors and breast cancer: Experiences of urban African American women. Health Educ Behav. 2006; 33(5):604-624. [PubMed: 16923833]

31. Fitzgibbon ML, Stolley MR, Schiffer L, Sanchez-Johnsen LA, Wells AM, Dyer A. A combined breast health/weight loss intervention for Black women. Prev Med. 2005; 40(4):373-383. [PubMed: 15530590]

32. Fitzgibbon ML, Stolley MR, Ganschow P, et al. Results of a faith-based weight loss intervention for Black women. J Natl Med Assoc. 2005; 97(10):1393-1402. [PubMed: 16355489]

33. Eyler AA, Baker E, Cromer L, King AC, Brownson RC, Donatelle RJ. Physical activity and minority women: A qualitative study. Health Educ Behav. 1998; 25(5):640-652. [PubMed: 9768383]

34. Nies MA, Vollman M, Cook T. African American women's experiences with physical activity in their daily lives. Public Health Nurs. 1999; 16(1):23-31. [PubMed: 10074819]

35. Bandura, A. Self-efficacy: The exercise of control. W.H Freeman; New York: 1997.

36. Rollnick S, Miller WR. What is motivational interviewing? Behavioural \& Cognitive Psychotherapy. 1995; 23:325-334.

37. Rollnick, S.; Mason, P.; Butler, C. Health Behavior Change: A Guide for Practitioners. Churchhill Livingstone; London: 1999.

38. Harel O, Zhou X-H. Multiple imputation: Review of theory, implementation and software. Stat Med. 2007; 26(16):3057-3077. [PubMed: 17256804]

39. Raghunathan TE. What do we do with missing data? Some options for analysis of incomplete data. Ann Rev Public Health. 2004; 25:99-117. [PubMed: 15015914]

40. U. S. Preventive Services Task Force. Screening for Obesity in Adults. Agency for Healthcare Research and Quality; Rockville: 2003.

41. Knowler WC, Barrett-Connor E, Fowler SE, et al. Reduction in the incidence of type 2 diabetes with lifestyle intervention or metformin. N Engl J Med. 2002; 346(6):393-403. [PubMed: 11832527]

42. Wood PD, Stefanick ML, Dreon DM, et al. Changes in plasma lipids and lipoproteins in overweight men during weight loss through dieting as compared with exercise. N Engl J Med. 1988; 319(18):1173-1179. [PubMed: 3173455]

43. Stevens VJ, Obarzanek E, Cook NR, et al. Long-term weight loss and changes in blood pressure: Results of the Trials of Hypertension Prevention, phase II. Ann Intern Med. 2001; 134(1):1-11. [PubMed: 11187414]

44. Tuomilehto J, Lindstrom J, Eriksson JG, et al. Prevention of type 2 diabetes mellitus by changes in lifestyle among subjects with impaired glucose tolerance. N Engl J Med. 2001; 344(18):13431350. [PubMed: 11333990]

45. Neter JE, Stam BE, Kok FJ, Grobbee DE, Geleijnse JM. Influence of weight reduction on blood pressure: A meta-analysis of randomized controlled trials. Hypertension. 2003; 42(5):878-884. [PubMed: 12975389]

46. Whelton PK, Appel LJ, Espeland MA, et al. Sodium reduction and weight loss in the treatment of hypertension in older persons: A randomized controlled trial of nonpharmacologic interventions in the elderly (TONE). TONE Collaborative Research Group. JAMA. 1998; 279(11):839-846. erratum appears in JAMA 1998;279(24):1954. [PubMed: 9515998]

47. Anonymous. Effects of weight loss and sodium reduction intervention on blood pressure and hypertension incidence in overweight people with high-normal blood pressure. The Trials of 
Hypertension Prevention, phase II. The Trials of Hypertension Prevention Collaborative Research Group. Arch Intern Med. 1997; 157(6):657-667. [PubMed: 9080920]

48. Hamman RF, Wing RR, Edelstein SL, et al. Effect of weight loss with lifestyle intervention on risk of diabetes. Diabetes Care. 2006; 29(9):2102-2107. [PubMed: 16936160]

49. Hollis JF, Gullion CM, Stevens VJ, et al. Weight loss during the intensive intervention phase of the Weight-Loss Maintenance Trial. Am J Prev Med. 2008; 35(2):118-126. [PubMed: 18617080]

50. West DS, Elaine Prewitt T, Bursac Z, Felix HC. Weight loss of black, white, and Hispanic men and women in the Diabetes Prevention Program. Obesity. 2008; 16(6):1413-1420. [PubMed: 18421273]

51. Diabetes Prevention Program Research Group. Achieving weight and activity goals among Diabetes Prevention Program lifestyle participants. Obes Res. 2004; 12(9):1426-1434. [PubMed: 15483207]

52. Appel LJ, Champagne CM, Harsha DW, et al. Effects of comprehensive lifestyle modification on blood pressure control: Main results of the PREMIER clinical trial. JAMA. 2003; 289(16):20832093. [PubMed: 12709466]

53. Hill JO, Wyatt H, Phelan S, Wing R. The National Weight Control Registry: Is it useful in helping deal with our obesity epidemic? J Nutri Educa Behav. 2005; 37(4):206-210.

54. Roth DL, Snyder CR, Pace LM. Dimensions of favorable self-presentation. J Pers Soc Psychol. 1986; 51(4):867-874.

55. Muhlheim LS, Allison DB, Heshka S, Heymsfield SB. Do unsuccessful dieters intentionally underreport food intake? Int J Eat Disord. 1998; 24(3):259-266. [PubMed: 9741036]

56. Jakicic JM, Polley BA, Wing RR. Accuracy of self-reported exercise and the relationship with weight loss in overweight women. Med Sci Sports Exerc. 1998; 30(4):634-638. [PubMed: 9565948]

57. Ward DS, Evenson KR, Vaughn A, Rodgers AB, Troiano RP. Accelerometer use in physical activity: Best practices and research recommendations. Med Sci Sports Exerc. 2005; 37(11 Suppl):S582-588. [PubMed: 16294121]

58. Kumanyika S, Grier S. Targeting interventions for ethnic minority and low-income populations. The Future of Children. 2006; 16(1):187-207. [PubMed: 16532664]

59. Kumanyika SK, Obarzanek E, Stettler N, et al. Population-based prevention of obesity: the need for comprehensive promotion of healthful eating, physical activity, and energy balance: A scientific statement from American Heart Association Council on Epidemiology and Prevention, Interdisciplinary Committee for Prevention (formerly the Expert Panel on Population and Prevention Science). Circulation. 2008; 118(4):428-464. [PubMed: 18591433]

60. Grier SA, Kumanyika SK. The context for choice: Health implications of targeted food and beverage marketing to African Americans. Am J Public Health. 2008; 98(9):1616-1629. [PubMed: 18633097]

61. Taylor JE, Poston WSC 2nd, Haddock CK, et al. Psychometric characteristics of the General WellBeing Schedule (GWB) with African-American women. Qual Life Res. 2003; 12(1):31-39. [PubMed: 12625516]

62. Glass TA, McAtee MJ. Behavioral science at the crossroads in public health: Extending horizons, envisioning the future. Soc Sci Med. 2006; 62(7):1650-1671. [PubMed: 16198467]

63. U.S. Preventive Services Task Force. The Guide to Clinical Preventive Services 2006: Recommendations of the U S Preventive Services Task Force. Washington: 2006.

64. Oliver JE, Lee T. Public opinion and the politics of obesity in America. J Health Polit Policy and Law. 2005; 30(5):923-954. [PubMed: 16477792] 


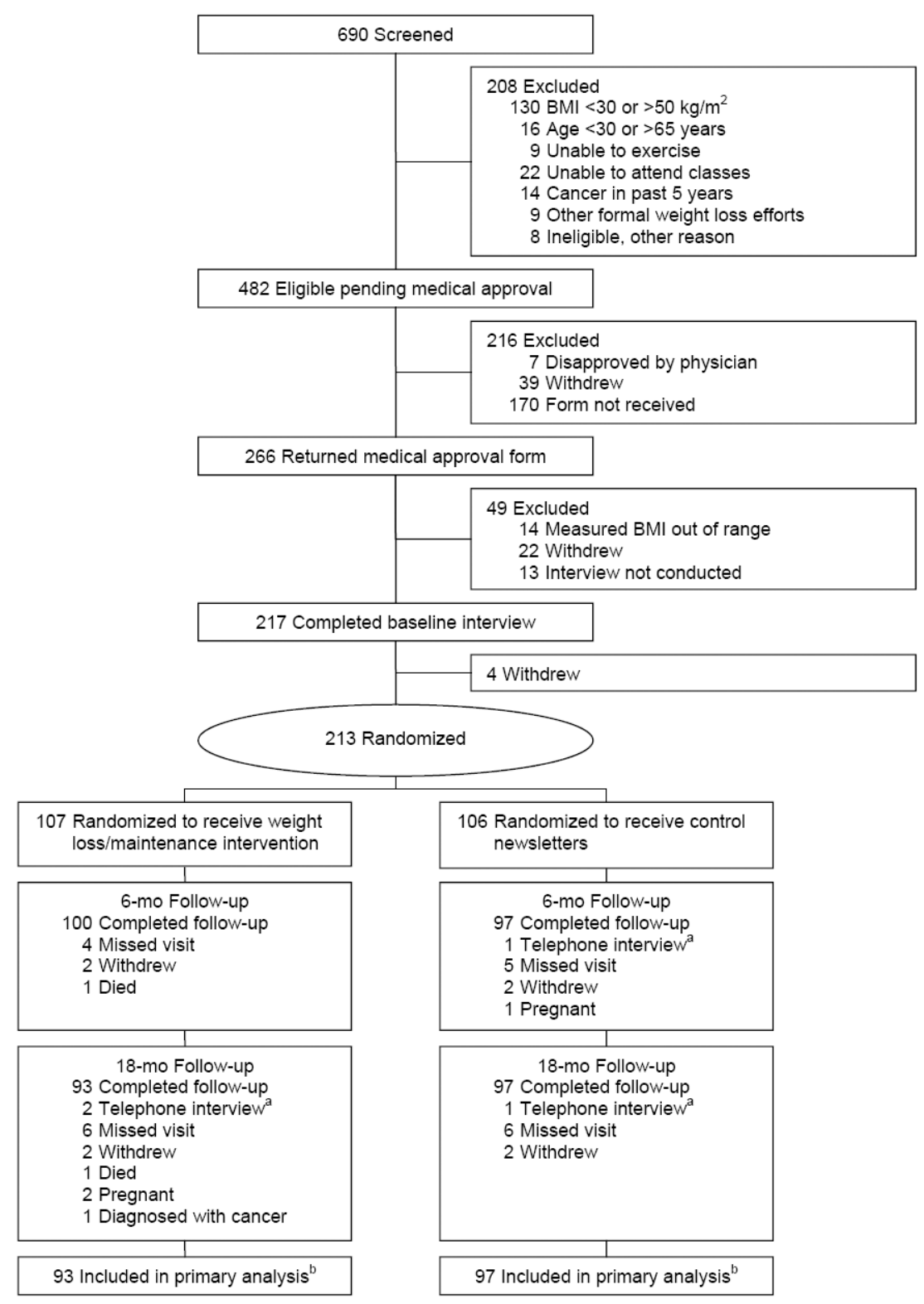

Figure 1.

ORBIT Enrollment, Randomization, and Follow-up

${ }^{\text {a }}$ Questionnaires completed by telephone, weight not measured.

${ }^{b}$ Only women who completed the 18-month follow-up were included in the primary analysis. However, a sensitivity analysis was conducted in which outcome data were imputed for participants with missing weight at follow-up. One analysis included all participants; another excluded the 4 women who died, had cancer, or were pregnant at 18month follow-up. 
Table 1

Baseline Characteristics of Randomized Participants

\begin{tabular}{|c|c|c|c|}
\hline & Intervention $(\mathrm{N}=107)$ & Control (N=106) & $\begin{array}{c}\text { All Randomized Women } \\
(\mathbf{N}=\mathbf{2 1 3})\end{array}$ \\
\hline Age, mean (SD), y & $46.4(8.4)$ & $45.5(8.4)$ & $46.0(8.4)$ \\
\hline Weight, mean (SD), kg & $103.9(15.7)$ & $105.9(17.4)$ & $104.9(16.6)$ \\
\hline BMI, mean (SD), $\mathrm{kg} / \mathrm{m}^{2}$ & $38.7(5.5)$ & $39.8(5.8)$ & $39.2(5.7)$ \\
\hline \multicolumn{4}{|l|}{ BMI obesity category, No. (\%) } \\
\hline Stage $1\left(30-<35 \mathrm{~kg} / \mathrm{m}^{2}\right)$ & $36(34 \%)$ & $27(25 \%)$ & $63(30 \%)$ \\
\hline Stage $2\left(35-<40 \mathrm{~kg} / \mathrm{m}^{2}\right)$ & $31(29 \%)$ & $26(25 \%)$ & $57(27 \%)$ \\
\hline Stage $3\left(\geq 40 \mathrm{~kg} / \mathrm{m}^{2}\right)$ & $40(37 \%)$ & $53(50 \%)$ & $93(44 \%)$ \\
\hline Education, mean (SD), y & $14.6(2.0)$ & $15.1(1.9)$ & $14.9(2.0)$ \\
\hline College graduate, No. $(\%)$ & $42(39 \%)$ & $52(49 \%)$ & $94(44 \%)$ \\
\hline $\begin{array}{l}\text { Household income } / y, \text { median }\left(25^{\text {th }}, 75^{\text {th }} \text { percentiles }\right) \text {, } \\
\$^{a}\end{array}$ & $42,500(30,000,62,500)$ & $42,500(30,000,62,500)$ & $42,500(30,000,62,500)$ \\
\hline Married or living with a partner, No. (\%) & $37(35 \%)$ & $36(34 \%)$ & $73(34 \%)$ \\
\hline Employed full-time, No (\%) & $77(72 \%)$ & $76(72 \%)$ & $153(72 \%)$ \\
\hline Energy intake, mean (SD), kcal/d $b$ & $2458(1088)$ & $2374(984)$ & 2418 (1037) \\
\hline Healthy Eating Index $b(31)$, mean (SD) & $52.7(12.3)$ & $55.2(10.8)$ & $53.9(11.7)$ \\
\hline $\begin{array}{l}\text { Physical activity }{ }^{c} \text {, median }\left(25^{\text {th }}, 75^{\text {th }} \text { percentiles }\right) \text {, } \\
\text { min/day }\end{array}$ & $84.3(31.4,190.7)$ & $86.4(51.4,175.7)$ & $85.4(40.7,175.7)$ \\
\hline
\end{tabular}

Abbreviations: BMI, body mass index, calculated as weight in kilograms divided by height in meters squared.

${ }^{a} \mathrm{~N}=208$ for income, due to missing data.

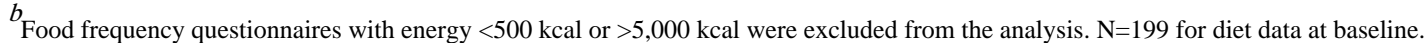

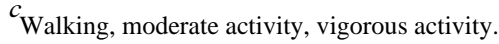


Table 2

Class Attendance for Intervention Group Participants ${ }^{a}$, ORBIT

\begin{tabular}{lcc}
\hline & Months 1-6 $\boldsymbol{b}$ & Months 7-18 \\
\hline Percentage of classes attended, mean (SD) & $53.0(31.5)$ & $27.1(30.2)$ \\
Attended no classes, No. (\%) & $9(8 \%)$ & $34(32 \%)$ \\
Attended $\geq 25 \%$ of classes, No., (\%) & $79(74 \%)$ & $42(39 \%)$ \\
Attended $\geq 50 \%$ of classes, No, (\%) & $62(58 \%)$ & $32(30 \%)$ \\
Attended $\geq 75 \%$ of classes, No., (\%) & $34(32 \%)$ & $8(7 \%)$ \\
\hline
\end{tabular}

${ }^{a} \mathrm{~N}=107$.

${ }^{b}$ Cohort 1 was offered 47 classes; cohort 2 was offered 46.

${ }^{c}$ Cohort 1 was offered 66 classes; cohort 2 was offered 61. 


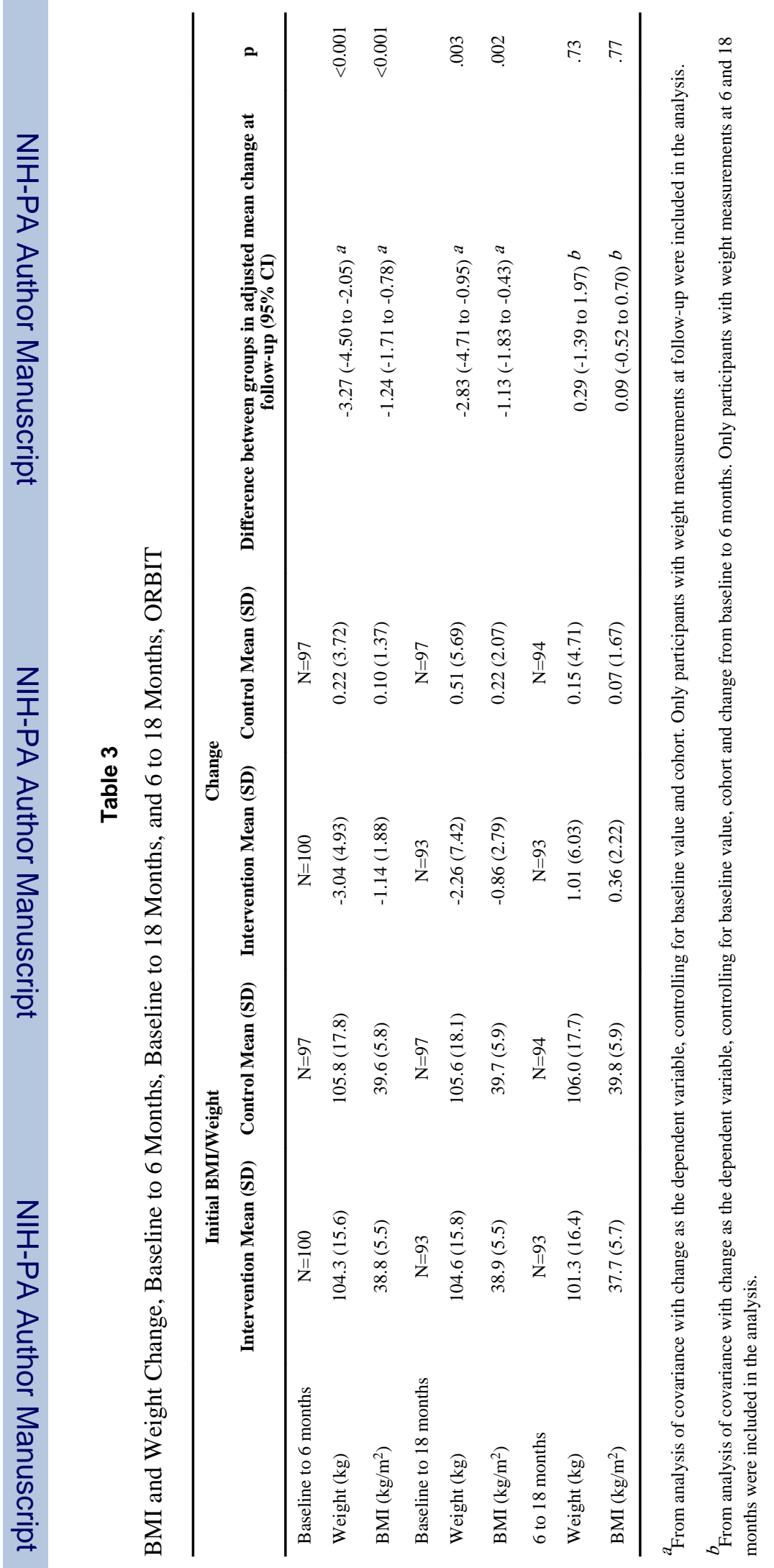

Obesity (Silver Spring). Author manuscript; available in PMC 2013 September 17. 
